\title{
Credit Constraints, Entrepreneurial Talent, and Economic Development
}

\author{
Milo Bianchi*
}

March 2009

\begin{abstract}
In this paper, we formalize the view that economic development requires high rates of productive entrepreneurship, and this requires an efficient matching between entrepreneurial talent and production technologies. We first explore the role of financial development in promoting such efficient allocation of talent, which results in higher production, job creation and social mobility. We then show how different levels of financial development may endogenously arise in a setting in which financial constraints depend on individual incentives to misbehave, these incentives depend on how many jobs are available, and this in turn depends on the level of financial development. Such complementarity between labour market and financial market development may generate highly divergent development paths even for countries with very similar initial conditions.
\end{abstract}

Keywords: credit constraints, allocation of entrepreneurial talent, productive and unproductive entrepreneurs, economic development

JEL classification: J24, L26, O16

Copyright (C) UNU-WIDER 2009

* Paris School of Economics, email: bianchi@pse.ens.fr

This study has been prepared within the UNU-WIDER project on Entrepreneurship and Development (Promoting Entrepreneurial Capacity), directed by Wim Naudé.

UNU-WIDER gratefully acknowledges the financial contributions to the project by the Finnish Ministry for Foreign Affairs, and the financial contributions to the research programme by the governments of Denmark (Royal Ministry of Foreign Affairs), Finland (Finnish Ministry for Foreign Affairs), Norway (Royal Ministry of Foreign Affairs), Sweden (Swedish International Development Cooperation AgencySida) and the United Kingdom (Department for International Development). 


\section{Acknowledgements}

I am grateful to Wim Naudé, Thomas Piketty and participants at MESS (Paris) for useful suggestions and to Région Ile-de-France for financial support.

The World Institute for Development Economics Research (WIDER) was established by the United Nations University (UNU) as its first research and training centre and started work in Helsinki, Finland in 1985. The Institute undertakes applied research and policy analysis on structural changes affecting the developing and transitional economies, provides a forum for the advocacy of policies leading to robust, equitable and environmentally sustainable growth, and promotes capacity strengthening and training in the field of economic and social policy making. Work is carried out by staff researchers and visiting scholars in Helsinki and through networks of collaborating scholars and institutions around the world.

www.wider.unu.edu

publications@wider.unu.edu

UNU World Institute for Development Economics Research (UNU-WIDER)

Katajanokanlaituri 6 B, 00160 Helsinki, Finland

Typescript prepared by the author

The views expressed in this publication are those of the author(s). Publication does not imply endorsement by the Institute or the United Nations University, nor by the programme/project sponsors, of any of the views expressed. 


\section{Introduction}

Entrepreneurship is generally recognized as a key factor for economic development. ${ }^{1}$ At the same time, the literature emphasizes that entrepreneurship is a very heterogeneous concept. For example, entrepreneurs differ in their motivations for starting a business, in their legal status, in their aspirations. ${ }^{2}$ We expect such characteristics to be a significant determinant of entrepreneurs' capacity to create jobs, innovation and generate economic growth (see Wennekers and Thurik (1999), Reynolds et al. (2002), Stel, Carree and Thurik (2005)).

In this paper, we focus on a basic distinction between more or less productive entrepreneurs. ${ }^{3}$ Individual productivity depends crucially on two dimensions. Entrepreneurial talent, which determines the output an individual can produce for a given technology, and access to more or less productive technologies. We then take the view that economic development requires an efficient allocation of talent, i.e. it requires that the most productive technologies are controlled by those who can get the most out of them.

One may think of several obstacles to such efficient matching, including corrupt bureaucracies, lack of information, or distorted incentives. We here concentrate on credit constraints. More productive technologies typically require a minimal capital investment in order to operate, so it may be impossible for poor individuals to access them, however talented these individuals may be. The severity of credit constraints will then affect, and will be affected by, the extent to which the most talented individuals have access to the most productive technologies, which in turn determines the level of economic development.

The aim of the paper is twofold. First, to analyze in a simple model how the interaction between entrepreneurial talent, production technologies and credit constraints determines the process of economic development. Second, to explore in such setting which forces may impede financial development, as determined in equilibrium, and then show how underdevelopment traps may arise.

For this purpose, we first build an occupational choice model in which individuals differ in their wealth and entrepreneurial talent. There are two ways in which production can take place. First, it can take place in firms, and

\footnotetext{
${ }^{1}$ As it is well known, this proposition goes back at least to Schumpeter (1934). van Praag and Versloot (2007) provide a recent review on the evidence of the economic value of entrepreneurship.

${ }^{2}$ See for example Reynolds, Bygrave, Autio, Cox and Hay (2002) on necessity vs. opportunity entrepreneurs; Schneider and Enste (2000) on formality vs. informality; Berner, Gomez and Knorringa (2008) on survival vs. growth enterprises.

${ }^{3}$ Less productive entrepreneurs will sometimes be called unproductive, which emphasizes that they may produce just enough to survive. This should however not be confused with rent-seeking activities.
} 
this requires a minimal amount of capital and salaried workers to operate. The lower is financial development, the higher is the collateral required to get a loan, and so the lower is the fraction of individuals who can consider setting up a firm. Second, production can take place in one-man businesses. These require no capital investment and no employee to operate, but they are constrained by inefficiently small scale of production. ${ }^{4}$

Depending on their wealth and talent, individuals then choose whether to set up a firm (and become entrepreneurs), run a one-man business (and become self-employed) or look for a job as employee in one of these firms. In this setting, relaxing credit constraints allows some poor individuals to access credit and set up a firm. This increases competition and the demand for labor, which in turn decreases the incentive to set up a firm for less talented individuals. Hence, the rich and untalented are induced to look for a salaried job while at the same time the poor and talented can become entrepreneurs. That is, financial development changes both the structure of production, as more individuals become entrepreneurs and less become self-employed, and it induces a more efficient allocation of entrepreneurial talent to production technologies. Both mechanisms generate an higher level of production.

We then enrich our framework in order to explore the impediments to financial development. In particular, we derive the level of financial development as an equilibrium outcome of a setting in which financial development depends on individual incentives to misbehave, which are affected by labor market conditions, and these in turn depend on the level of financial development. The purpose is to address the question of why countries may end up with low levels of financial development and then to highlight a possible mechanism behind underdevelopment traps.

The basic ingredients are standard. First, individual interest to get a loan need not be aligned with banks' interest to get the loan repaid. In particular, we assume that individuals may ask for capital and not invest it efficiently, as this generates private benefits (as e.g. in Holmstrom and Tirole (1997)). ${ }^{5}$ Second, banks find it very difficult to detect ex-ante those individuals who ask for loans even if they will not repay. In particular, we assume that, while profits are verifiable, banks cannot observe entrepreneurial talent. Hence, as usual, banks need a sufficiently high collateral in order to make sure that entrepreneurs will not to misbehave. In this setting, however, the required level of collateral is determined by, and at the same it determines, labor market conditions.

These interlinkages open the possibility of multiple equilibria. If entre-

\footnotetext{
${ }^{4}$ See for example Banerjee and Duflo (2008) for a detailed account of this type of self-employment in developing countries.

${ }^{5}$ There are several other reasons why this could happen. For example, in a setting in which profits are stochastic, entrepreneurs may take too much risk as they are protected by limited liability or as they overestimate their probability of success.
} 
preneurs are a few, labor demand is low so individuals may ask for a loan even if not particularly talented, since their outside option is poor. This means that banks face many potentially problematic requests and they have to ask for high levels of collateral to screen applicants. This in turn sustains low levels of entrepreneurship. Conversely, if entrepreneurs are many, labor demand is high so the probability of ending up with a salaried job is high and only talented individuals ask for loans. Receiving a few problematic requests, banks do not need an high collateral, which in turn sustains high rates of entrepreneurship.

It follows that countries with very similar initial conditions may experience very different levels of development. Consider for example two countries with the same low level of financial development and with slightly different wealth distributions. In the first country, basically no one is wealthy enough to set up a firm. In the second country, instead, there are a few wealthy individuals who can set up a firm even without asking for a loan. If one then tries to increase financial development, the first country will face severe agency problems, for the reasons just explained, and as a result it will get stuck in an equilibrium with low financial development, low entrepreneurship and low production. The second country instead will converge to an equilibrium with high financial development, high entrepreneurship and high production. As we show in Section 5, the difference in initial wealth distributions between the two countries can be minimal and still lead one country to take off and the other to stagnate.

\section{Relation with the literature}

This paper is linked to several streams of literature. First, it builds on models of occupational choice in which entrepreneurial talent is heterogeneous, as pioneered by Lucas (1978). ${ }^{6}$ In particular, we focus on the allocation of entrepreneurial talent across occupations with different productivity, as in the spirit of Baumol (1990), Murphy, Shleifer and Vishny (1991), Acemoglu (1995) and Holmes and Schmitz (2001). This literature typically emphasizes distortions in the structure of rewards within a society, while we focus on credit constraints as an impediment to the efficient allocation of talent.

Second, this work relates to the literature on the effects of financial development (see Levine (2005) for a recent survey), and specifically to models analyzing occupational choices with credit constraints and nonconvex production technologies (see e.g. Banerjee and Newman (1993), Aghion and Bolton (1997), Ghatak and Jiang (2002); and Banerjee (2003) for a review). Similarly to these models, we emphasize how initial conditions, and specifically the distribution of wealth, may lead to poverty traps. However, we

\footnotetext{
${ }^{6}$ See e.g. Parker (2004) and Bianchi and Henrekson (2005) for a review of such models of entrepreneurship.
} 
consider individuals with different entrepreneurial talent and then focus on the allocation of talent across occupations.

A closely related approach is taken by Lloyd-Ellis and Bernhardt (2000), who formalize the process of development as driven by the interaction between entrepreneurial efficiency and credit constraints. In such model, depending on the distribution of entrepreneurial efficiency, the economy can reach an equilibrium with an efficient structure of production or get stuck with a dual structure in which some individuals remain employed in a subsistence agricultural sector. We share these basic mechanisms, but our focus is more in how the process of development depends on credit constraints and in how equilibria with low financial development may be sustained.

Last, by deriving access to credit as an equilibrium outcome, we may contribute to literature on the determinants of financial development. The role of institutions and in particular of legal origins has been widely emphasized. La Porta, Lopez-de Silanes, Shleifer and Vishny (1998), and a vast ensuing literature, argue that better investor protection allowed for greater financial market development in common law countries. More recently, political economy distortions have been documented: financial development, despite boosting efficiency, is likely to create winners and losers. If losers, say incumbent firms, are sufficiently powerful, then the process of development may be blocked (see Rajan and Zingales (2003)). While this view is consistent with the dynamics of our model (profits of incumbent entrepreneurs will decrease with financial development), we take a complementary route and derive underdevelopment traps from standard economic reasons, i.e. moral hazard and information asymmetry.

\section{The model}

The economy is populated by a continuum $n$ of risk-neutral individuals, who are heterogeneous in terms of initial wealth $a$ and entrepreneurial talent $t .^{7}$ Wealth is drawn from a cumulative distribution function $F$ with support on $\mathbb{R}_{+}$; talent from a cumulative distribution function $G$ with support on the interval $[\underline{t}, \bar{t}]$ in $\mathbb{R}_{+}$. These draws are assumed to be statistically independent. In addition, each individual is endowed with one unit of labor, which he can use as follows: he can set up a firm, look for a job as employee of such firm, or run a one-man business. We now describe these options in further detail.

\subsection{Production technologies}

There is a single good in the economy which can be produced by firms and by one-man businesses. We assume that each firm has the same size in

\footnotetext{
${ }^{7}$ We here abstract from different attitudes toward risk as a driving force of occupational choices (see Kihlstrom and Laffont (1979) for a formalization of this view and Bianchi and Henrekson (2005) for a discussion).
} 
terms of capital and labor, it employs $k$ units of capital and $l$ workers. ${ }^{8}$ The output produced depends however on entrepreneurial talent. A firm run by an individual with talent $t$ produces $t f(k, l)$ units of output, where $f(k, l)$ is a common production technology. ${ }^{9}$ We normalize $f(k, l)=1$, so the profit of one such firm writes as

$$
\pi=p t-w l-r k
$$

where $p$ denotes the price of the good, $w$ denotes workers' wage, and $r$ is the market interest rate.

If the capital investment falls short of $k$, production can only take place in one-man businesses. These businesses require no capital, no employees, and their output does not depend on entrepreneurial talent. ${ }^{10}$ In order to emphasize that production in these businesses is inefficient, we take the extreme view that an individual who run a one-man business can get just enough for his own consumption (and we normalize such quantity to zero). ${ }^{11}$

Individuals who set up a firm are called entrepreneurs, they enjoy utility $U_{1}=\pi$, and we denote their population share with $x_{1}$. Individuals who work as employee in one such firms are called workers, they enjoy utility $U_{2}=w$ and we denote their population share with $x_{2}$. Individuals who run a one-man business are called self-employed, they enjoy utility $U_{3}=0$ and their population share is denoted with $x_{3}$.

\subsection{Markets}

There are three markets in our economy: a labor market, a product market, and a credit market. In the labor market, the wage $w$ is fixed and exogenous, which implies that such market may not clear. In case of excess supply, each applicant has the same probability of getting a job. ${ }^{12}$ The number of workers equals firms' demand, so we have

$$
x_{2}=l x_{1} .
$$

The product market is described by a decreasing inverse demand function

$$
p=P(Q),
$$

\footnotetext{
${ }^{8}$ The effects of financial development in our model would be amplified if the amount of capital invested and the number of employees were a function of one's talent.

${ }^{9}$ This formalization of entrepreneurial talent follows Lucas (1978), and several subsequent occupational choice models (e.g. Gollin (2007)).

${ }^{10}$ Our conclusions would hold if small businesses and big firms produced different goods and both production functions depended on individual talent.

${ }^{11}$ Formally, we assume that $f(K,)=$.0 for every $K<k$. Our results would hold as long as labor is less efficient in one-man businesses than in firms (i.e. $(1+l)$ one-man businesses produce less than one of the firms, even when such firm is managed by the least talented individual). In this sense, we talk about more or less efficient production technologies.

${ }^{12}$ As we will see, there cannot be excess demand in our economy. More sophisticated reasons for non-market clearing wages are for example in Weiss (1980) and Shapiro and Stiglitz (1984).
} 
where $Q$ denotes the total output produced for the market. Entrepreneurs take the price $p$ as given, and inelastically supply their output.

The credit market is competitive, the interest rate $r$ is fixed and exogenous. Individuals can ask for a loan $(k-a)$ in order to set up a firm, but we assume that only sufficiently wealthy individuals can get a loan. The lower bound on wealth is defined as

$$
a \geq a^{*} .
$$

While in Section 5 we derive such threshold as an equilibrium outcome, for now we take $a^{*}$ as exogenous. We say that a country is more financially developed the lower is the amount of personal wealth needed as collateral in order to set up a firm, i.e. the lower is $a^{*}$.

\subsection{Equilibrium}

In equilibrium, each individual, given his wealth and talent, chooses an option in order to maximize his expected utility; everyone is given one occupation, so

$$
x_{1}+x_{2}+x_{3}=1 ;
$$

and the markets function according to equations (2), (3) and (4).

In order to characterize such equilibrium, consider first the choice of an individual with wealth lower than $a^{*}$, who cannot afford to set up a firm. Since $U_{2} \geq U_{3}$ irrespective of $t$, his choice is pretty trivial: he applies for a job as employee, and, if he is not assigned one, he becomes self-employed. A more interesting case concerns an individual with wealth greater than $a^{*}$. Given his talent $t$, he sets up a firm if and only if

$$
p t-w l-r k \geq \frac{x_{2}}{1-x_{1}} w,
$$

where the right hand side is the expected payoff of looking for a job (i.e. the sum of the utility as worker, weighted by the probability to be hired, and as self-employed, which we have normalized to zero). Equation (6) implicitly defines a lower bound on the talent of entrepreneurs as

$$
t^{*}=\frac{w l+\left(1-x_{1}\right) k}{\left(1-x_{1}\right) p} .
$$

Hence, provided that an equilibrium exists, the share of entrepreneurs $x_{1}$ is implicitly defined by

$$
x_{1}=\left[1-F\left(a^{*}\right)\right]\left[1-G\left(t^{*}\right)\right] .
$$

We are then interested in identifying the conditions for the existence and uniqueness of an equilibrium in our economy. We first notice that the price 
of the good decreases with the share of entrepreneurs in the population, as shown in the next Lemma. ${ }^{13}$

Lemma 1 The price $p$ is decreasing in the share of entrepreneurs $x_{1}$.

We then notice that, given Lemma 1 , the minimal talent needed to run profitably a firm increases with the share of entrepreneurs $x_{1}$. In fact, an higher $x_{1}$ reduces the incentive to set up a firm both because it increases competition and because it increases the demand for workers, thereby reducing the probability of ending up self-employed. This is expressed in the next Lemma.

Lemma 2 The minimal talent $t^{*}$ is increasing in the share of entrepreneurs $x_{1}$.

Finally, in order to ensure the existence of the equilibrium, we need to rule out the possibility of excess labor demand. In fact, given that each firm has to employ $l$ workers, the share of entrepreneurs is bounded above from $1 /(1+l)$. When $x_{1}=0$, setting up a firm is most profitable, and by equation (7) the minimal talent required is

$$
t_{0}^{*} \equiv \frac{w l+k}{\bar{p}},
$$

where $\bar{p} \equiv P(0)$. We then assume that

$$
0<1-G\left(t_{0}^{*}\right) \leq \frac{1}{1+l},
$$

which implies that the amount of individuals who prefer to be workers is always sufficient to meet firms' demand. In fact, since by Lemma 2 the right hand side of equation (8) is decreasing in $x_{1}, x_{1}$ never exceeds $1 /(1+l)$ and so labor demand never exceeds $l /(1+l)$. Moreover, labor supply is always $\left(1-x_{1}\right)$, which never falls short of $l /(1+l)$.

Hence, condition (9) ensure that an equilibrium in our economy exists and it is unique. Equation (8) uniquely defines the share of entrepreneurs $x_{1}$ and, together with equations (2) and (5), this characterizes our equilibrium. We summarize with the following Proposition.

Proposition 1 Under condition (9), an equilibrium exists and it is unique. It is defined by equations (2), (5) and (8).

\footnotetext{
${ }^{13}$ All omitted proofs are provided in the Appendix.
} 


\section{Effects of financial development}

In our model, financial development affects the equilibrium number and average talent of entrepreneurs. In particular, by relaxing wealth constraints, financial development allows the poor with high talent to become entrepreneurs. As a result, the share of entrepreneurs and their average talent increase. This is formalized in the next Lemma.

Lemma 3 The share of entrepreneurs $x_{1}$ is increasing in financial development.

This Lemma has a number of implications, which describe the ways in which an higher rate of productive entrepreneurs generates economic development in our setting.

First, financial development allows more jobs to be created. By increasing labor demand, an increase in financial development induces more individuals to become workers and less individuals to become self-employed. This follows directly from equations (2) and (5).

Second, financial development induces a more efficient allocation of entrepreneurial talent to production technologies. In fact, when credit constraints are relaxed, some poor but talented self-employed have the possibility to leave their one-man businesses and become entrepreneurs and others have the possibility to become salaried workers. At the same time, the rich and untalented individuals are induced to leave their firm and look for a salaried job (see Lemma 2). In this sense, financial development spurs also social mobility.

Third, even keeping talent constant, a higher rate of entrepreneurship and a lower rate of self-employment imply that labor resources in the economy are applied more efficiently. Hence, total production increase and, as an immediate corollary, the consumption good becomes cheaper to buy (see Lemma 1). We summarize these effects in the following Proposition.

Proposition 2 An increase in financial development induces

a. More individuals to become entrepreneurs and fewer individuals to become self-employed;

b. A more efficient allocation of entrepreneurial talent to production technologies;

c. Job creation and social mobility;

d. Higher production and cheaper consumption good.

\section{Impediments to financial development}

In this Section we extend the previous setting and derive the level of financial development as an equilibrium outcome. The purpose is to address how low 
levels of financial development may be sustained in equilibrium and how underdevelopment traps may then arise.

Specifically, we assume that, while entrepreneurial profits are verifiable, credit may be constrained as borrowers need not invest the loan efficiently. We refer to such inefficient way of investing as capital diversion. Since the firm cannot function if capital investment falls short of $k$, the borrower either diverts the entire capital or none of it. Diverting capital requires employing one's unit of labor (which implies that borrowers cannot get capital to set up a firm and at the same time look for a job as employees) and it generates private non verifiable benefits $b>0$. This creates a wedge between private and social returns from entrepreneurship: given $b>0$, an individual may ask for a loan even if he will have no money to pay it back.

It follows that, when lending money, banks must make sure that capital is not diverted. An individual with wealth $a$ and talent $t$ prefers not to divert capital if

$$
t p-w l-r(k-a) \geq b,
$$

which defines a lower bound on entrepreneurial talent as

$$
\tilde{t}=\frac{b+w l+r(k-a)}{p} .
$$

If banks could screen applicants according to their talent, the market would function perfectly as only sufficiently talented individuals (those with $t \geq \tilde{t}$ ) would get a loan and these individuals would never divert capital. This is however impossible since banks cannot observe entrepreneurial talent. Alternatively, banks can ask for a level of collateral which is common to everyone. In fact, notice from (10) that $\tilde{t}$ decreases with $a$, so the higher is personal wealth the less likely is that an individual of unknown talent has incentive to divert capital.

As shown in the next Lemma, banks set this minimal collateral $a^{*}$ in order to make sure that, conditional on asking for a loan, an individual has no incentive to divert capital. This writes as

$$
\tilde{t} \leq t^{*}
$$

or, rearranging in terms of a lower bound on wealth, as

$$
a \geq b-\frac{x_{2}}{1-x_{1}} w .
$$

Lemma 4 From condition (12), the equilibrium collateral $a^{*}$ is implicitly defined as a fixed point of the function

$$
h\left(a^{*}\right)=b-\frac{x_{2}\left(a^{*}\right)}{1-x_{1}\left(a^{*}\right)} w .
$$


Similarly to the previous analysis, we say that a country is more financially developed the lower is the amount of personal wealth needed as collateral in order to set up a firm. Our main interest is in showing how in this setting different levels of financial development may be sustained in equilibrium. In this case, depending on initial conditions, countries may converge either to an equilibrium with low financial development, low entrepreneurship and low production or to an equilibrium with high financial development, high entrepreneurship and high production.

The key mechanism which sustains the possibility of multiple equilibria is that the higher is the level of collateral needed, the higher is the incentive to divert capital, since the lower is the share of entrepreneurs and hence the probability of getting a job, which in turn sustains the need to ask for an high level of collateral; and vice versa. Formally, this means that $h\left(a^{*}\right)$ is increasing in $a^{*}$.

We simplify the following exposition by assuming that wealth is distributed uniformly over the interval $[0, \bar{a}]$, and we notice that $h\left(a^{*}\right)$ is concave in $a^{*}$. That is, the above effect is relatively weaker when the required collateral is very high, since at that level the probability of getting a job is already very small. These relations are expressed in the following Lemma.

Lemma 5 The function $h\left(a^{*}\right)$ is increasing and concave.

Given the shape defined in Lemma 5 , the function $h\left(a^{*}\right)$ can have either one, two or no fixed point for $a^{*} \in(0, k)$. (see the Example below for a graphical illustration.) If $h(k)<k$ and $h(0)>0$, then equation (13) uniquely defines an equilibrium level of financial development $a^{*} \in(0, k)$. In fact, in this case, banks are never better off by avoiding lending altogether. Sufficiently wealthy individuals, and in particular those with wealth $a \geq h(k)$, always invest the capital efficiently and so pay back the loan. On the other hand, also lending money irrespective of the collateral is not an equilibrium, since there are always sufficiently untalented individuals who are better off by getting the loan and diverting capital rather than working for a wage. Hence, in this case, we have a unique equilibrium and this equilibrium is stable and interior. That is, irrespective of the initial level of financial development, the country will converge to a unique $a^{*} \in(0, k)$. In the next Proposition, we show that a sufficient condition for this scenario to occur is that $b \in(w, k) .{ }^{14}$

For our purposes, a more interesting case is when $h(k)<k$ and $h(0) \leq 0$ since in this case market conditions affect financial development, which in turn affects market conditions, hence multiple equilibria may arise. ${ }^{15} \mathrm{In}$

\footnotetext{
${ }^{14}$ It is indeed customary (and intuitive) to assume that diversion is inefficient in the sense that $b \leq k$ (see for example Burkart, Gromb and Panunzi (1998)).

${ }^{15}$ In the Appendix we complete the analysis by considering the remaining cases, which however show similar mechanisms to the one highlighted here.
} 
this case, if the financial market is functioning well and banks lend money without asking for collateral $\left(a^{*}=0\right)$, then this is an equilibrium. In fact, untalented individuals have the incentive to look for a job as the share of entrepreneurs is high and so the probability of getting a job is high and so banks can be confident that only sufficiently talented individuals ask for loans and they pay back. This in turn sustains the fact that no collateral is needed.

The question is under which conditions a country starting at low levels of financial development can converge to such attractive scenario. As we show in the Appendix, if $h\left(a^{*}\right)$ admits either one or two fixed points, the economy can reach the virtuous equilibrium only by jumping at a sufficiently high level of financial development, while a gradual increase would lead the economy to get stuck at low levels of financial development. For the economy to converge to $a^{*}=0$ irrespective of the initial level of financial development, we must have no interior fixed point of $h\left(a^{*}\right)$. In this case, even a country with no financial market can open up one and converge to a virtuous equilibrium with many entrepreneurs, many salaried jobs, high production, an efficient allocation of talent and so on..

The occurrence of this scenario depends very much on such country's initial conditions. Starting in a situation with no financial markets, this scenario is more likely to occur the lower is $h(k)$, i.e. when enough individuals can set up a firm without asking for a loan. This implies that once a financial market is opened, labor demand is already sufficiently high to induce untalented individuals to look for a job as employees. Hence, banks can safely extend credit and induce the virtuous equilibrium described above. Moreover, one may switch from a situation in which this scenario can occur to a situation in which this scenario cannot occur with a minimal variation of initial conditions. In particular, in the next Example, we consider the role of the initial wealth distribution. Before that, we formalize the above arguments in the next Proposition.

Proposition 3 If $b \in(w, k)$, then equation (13) uniquely defines an equilibrium level of financial development $a^{*} \in(0, k)$. Otherwise multiple equilibria may arise, and countries with slightly different initial conditions may experience greatly diverging development paths.

\subsection{Example}

We now illustrate the mechanics of the above model with a closed form example. Suppose that talent is distributed uniformly over the interval $[0, \bar{t}]$ and wealth is distributed uniformly over the interval $[0, \bar{a}]$ and that the price $p$ is exogenous (Lemma 2 and the ensuing analysis would still work if $\left.\partial P / \partial x_{1}=0\right)$. Suppose also that $k=1, b=0.95, p=24, w=1, l=1$ and $\bar{t}=0.25$. These numbers ensure that $h(k)<k$ and $h(0)<0$, which is the 


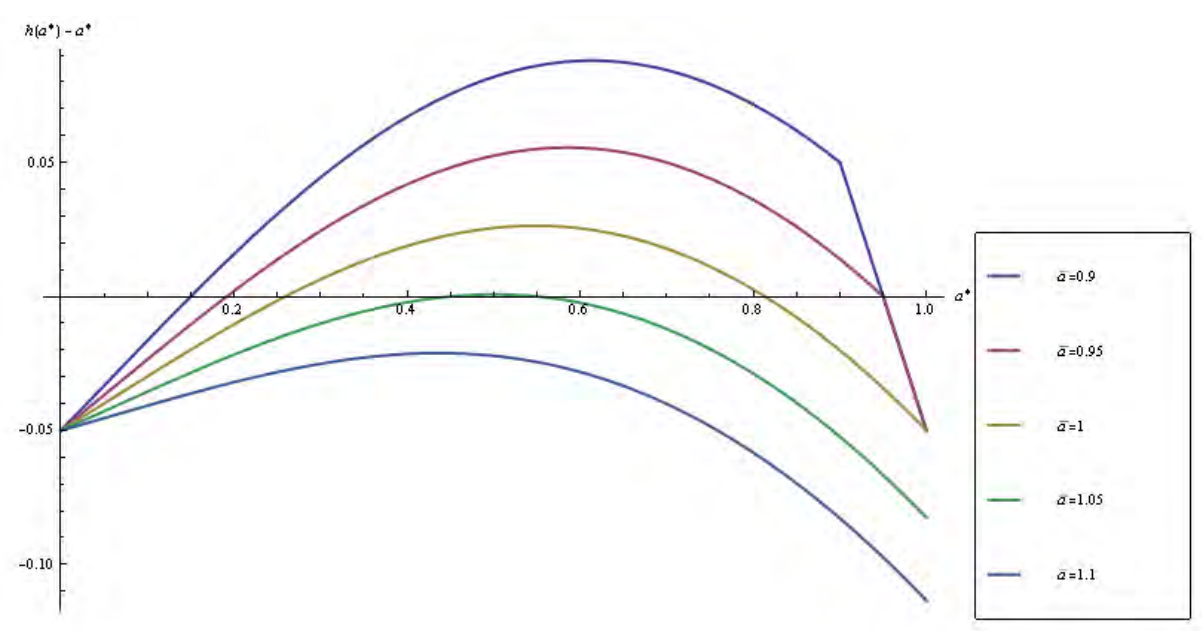

Figure 1: This Figure plots the function $h\left(a^{*}\right)-a^{*}$ for different levels of $\bar{a}$. The intersection with the horizontal axis represents the set of fixed points of equation (13), i.e. the equilibrium levels of financial development sustainable for a given wealth distribution.

most interesting case for our analysis.

We then concentrate on how the equilibrium depends on $\bar{a}$, which describes the initial wealth distribution. This is crucial as it determines the fraction of individuals who can set up a firm when access to credit is low or completely absent. We first consider which levels of financial development can be sustained in equilibrium, as determined by equation (13). Figure 1 reports the results for $\bar{a} \in\{0.9,0.95,1,1.05,1.1\}$. (higher $\bar{a}$ correspond to lower curves.)

These curves converge to the same point as $a^{*} \rightarrow 0$ since when everyone can get credit the initial distribution of wealth is irrelevant. When $a^{*}$ increases these curves diverge since the lower is $\bar{a}$, the lower is the fraction of individuals with wealth higher than $a^{*}$, the lower is the fraction of entrepreneurs, the lower the demand for labor and thus the higher is the incentive to ask for a loan and divert capital. The intersection of the plotted curves with the horizontal axis represents the set of fixed points of equation (13), i.e. the equilibrium levels of financial development sustainable for a given wealth distribution.

We now see that the lower is $\bar{a}$, the lower is the level of financial development at which a country may end up. Suppose we start in a situation with no financial development, in which no borrowing is possible, $\hat{a}=k$. We look at how initial conditions, and in particular initial wealth distribution, determines such country's development. We see from Figure 1 that when $\bar{a} \leq 0.95$, the country gets stuck with $a^{*}=0.95$ (which equals $b$ in 
our example). For $\bar{a} \in(0.95,1.05]$, the country gets stuck at some $a^{*} \geq 0.5$ (where such $a^{*}$ increases in $\bar{a}$ ). When instead $\bar{a}>1.05$, the country reaches the virtuous equilibrium with $a^{*}=0$.

It follows that countries with very similar initial conditions may reach very different levels of financial development, entrepreneurship and production. In our example, a country with $\bar{a}=0.95$ ends up in an equilibrium with $a^{*}=0.95, x_{1}=0$ and no market production $(Q=0)$, while a country with $\bar{a}$ just above 1.05 reaches the virtuous equilibrium. Figure 2 shows such patterns in our example. Since $k=1, \bar{a}=1$ is the threshold above which the country is sufficiently rich to have some individuals who can set up a firm even without getting a loan. Around such threshold, the equilibrium jumps abruptly from the minimal level of entrepreneurship $x_{1}=0$ to the maximum level of entrepreneurship (which in this case is $x_{1}=0.5$ since $l=1$.)

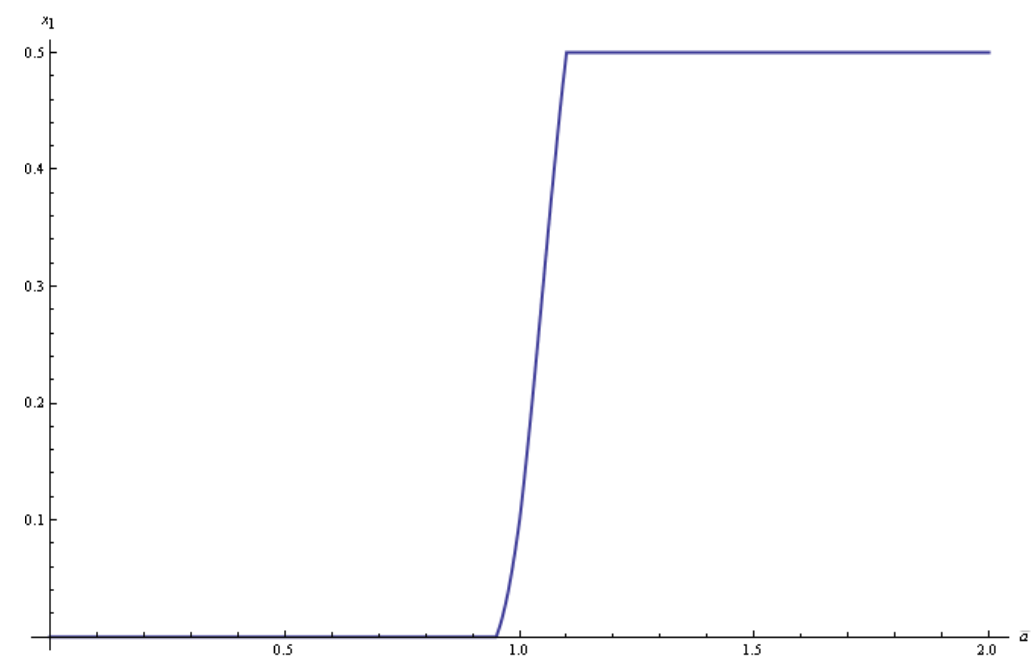

Figure 2: This Figure represents the level of entrepreneurship which can be sustained in equilibrium as one varies the initial wealth distribution (as described by $\bar{a}$ ).

\section{Conclusion}

This paper started with the idea that economic development requires a high rate of productive entrepreneurs. It has first developed a simple model to analyze the interaction between entrepreneurial talent, production technologies and credit constraints in shaping the process of economic development. We have shown how, by relaxing credit constraints, financial development promotes higher production, job creation, and social mobility.

We have then explored which forces may impede the development of 
a financial market in a setting in which financial development depends on individual incentives to misbehave and these in turn depend on the level of financial development. We have discussed in particular the role of initial wealth distribution in determining the possibility of underdevelopment traps.

The latter set of results emphasize that while financial development may induce economic development in several ways, some of which have been detailed in the above analysis, it is difficult to think of financial development as a process occurring in vacuo. That is, attempts to develop credit markets will be successful under some conditions and unsuccessful under others. As mentioned in the Introduction, some recent literature has emphasized the role of inherited institutions and interest groups in determining such conditions. We have instead emphasized standard market conditions, whereby a large supply of credit can be sustained in equilibrium only when enough entrepreneurs have started their business and labor demand is high enough to assure that capital will be invested efficiently. In this respect, our analysis suggests that complementarities are likely to arise between labor market and financial market development.

These dynamics also show that there are situations in which a gradual improvement in financial development is bound to be unsuccessful. If markets are not functioning well and individuals have incentive to misbehave, financial development will bounce back to its original low levels. This makes precise a sense in which, in these situations, the country needs a big push in order to escape the poverty trap.

\section{References}

Acemoglu, D. (1995), 'Reward structures and the allocation of talent', European Economic Review 39(1), 17-33.

Aghion, P. and Bolton, P. (1997), 'A theory of trickle-down growth and development', Review of Economic Studies 64(2), 151-72.

Banerjee, A. V. (2003), Contracting Constraints, Credit Markets, and Economic Development, in 'Advances in Economics and Econometrics: Theory and Applications: Eighth World Congress', Cambridge University Press.

Banerjee, A. V. and Duflo, E. (2008), 'What is middle class about the middle classes around the world?', Journal of Economic Perspectives 22(2), 328.

Banerjee, A. V. and Newman, A. F. (1993), 'Occupational choice and the process of development', Journal of Political Economy 101(2), 274-98. 
Baumol, W. (1990), 'Entrepreneurship: Productive, Unproductive, and Destructive', Journal of Political Economy 98(5), 893.

Berner, E., Gomez, G. and Knorringa, P. (2008), 'Helping a Large Number of People Become a Little Less Poor: The Logic of Survival Entrepreneurs', Mimeo. ISS, The Hague.

Bianchi, M. and Henrekson, M. (2005), 'Is neoclassical economics still entrepreneurless?', Kyklos 58(3), 353-377.

Burkart, M., Gromb, D. and Panunzi, F. (1998), 'Why Higher Takeover Premia Protect Minority Shareholders', Journal of Political Economy 106(1), 172-204.

Ghatak, M. and Jiang, N. (2002), 'A Simple Model of Inequality, Occupational Choice and Development', Journal of Development Economics 69(1), 205-226.

Gollin, D. (2007), 'Nobody's business but my own: Self employment and small enterprise in economic development', Journal of Monetary Economics Forthcoming.

Holmes, T. and Schmitz, A. (2001), 'A gain from trade: From unproductive to productive entrepreneurship', Journal of Monetary Economics 47(2), 417-446.

Holmstrom, B. and Tirole, J. (1997), 'Financial intermediation, loanable funds, and the real sector', Quarterly Journal of Economics $\mathbf{1 1 2}(3), 663-91$.

Kihlstrom, R. E. and Laffont, J.-J. (1979), 'A general equilibrium entrepreneurial theory of firm formation based on risk aversion', Journal of Political Economy 87(4), 719-48.

La Porta, R., Lopez-de Silanes, F., Shleifer, A. and Vishny, R. (1998), 'Law and Finance', Journal of Political Economy 106(6), 1113-1155.

Levine, R. (2005), Finance and growth: Theory and evidence, in P. Aghion and S. Durlauf, eds, 'Handbook of Economic Growth', Vol. 1 of Handbook of Economic Growth, Elsevier, chapter 12, pp. 865-934.

Lloyd-Ellis, H. and Bernhardt, D. (2000), 'Enterprise, Inequality and Economic Development', Review of Economic Studies 67(1), 147-168.

Lucas, R. E. J. (1978), 'On the size distribution of business firms', Bell Journal of Economics 9(2), 508-523. 
Murphy, K., Shleifer, A. and Vishny, R. (1991), 'The Allocation of Talent: Implications for Growth.', Quarterly Journal of Economics 106(2), 503-30.

Parker, S. (2004), The Economics of Self-Employment and Entrepreneurship, Cambridge University Press.

Rajan, R. and Zingales, L. (2003), 'The great reversals: the politics of financial development in the twentieth century', Journal of Financial Economics 69(1), 5-50.

Reynolds, P., Bygrave, W., Autio, E., Cox, L. and Hay, M. (2002), Global Entrepreneurship Monitor: 2002 executive report, Babson College.

Schneider, F. and Enste, D. H. (2000), 'Shadow economies: Size, causes, and consequences', Journal of Economic Literature 38(1), 77-114.

Shapiro, C. and Stiglitz, J. E. (1984), 'Equilibrium unemployment as a worker discipline device', American Economic Review 74(3), 433-44.

Stel, A., Carree, M. and Thurik, R. (2005), 'The Effect of Entrepreneurial Activity on National Economic Growth', Small Business Economics 24(3), 311-321.

van Praag, C. M. and Versloot, P. H. (2007), 'What is the value of entrepreneurship? a review of recent research', IZA Discussion Paper No. 3014 .

Weiss, A. W. (1980), 'Job queues and layoffs in labor markets with flexible wages', Journal of Political Economy 88(3), 526-38.

Wennekers, S. and Thurik, R. (1999), 'Linking Entrepreneurship and Economic Growth', Small Business Economics 13(1), 27-56. 


\section{Omitted Proofs}

Lemma 1 The price $p$ is decreasing in the share of entrepreneurs $x_{1}$.

Proof. The output writes

$$
Q=n x_{1} \hat{t}
$$

where $\hat{t}$ is the average talent of an entrepreneur, as determined in equilibrium. Differentiating equation (14) we write

$$
\frac{\partial Q}{\partial x_{1}}=\left(\hat{t}+\frac{\partial \hat{t}}{\partial x_{1}} x_{1}\right) n
$$

Now notice that it is always the case that

$$
\hat{t}+\frac{\partial \hat{t}}{\partial x_{1}} x_{1} \geq \underline{t} .
$$

In fact, since $t$ is bounded below from $\underline{t}, \partial \hat{t} / \partial x_{1}$ always exceeds $(\underline{t}-\hat{t}) / x_{1}$. Since $\underline{t} \geq 0$, equation (15) is positive. Given equation (3) $p$ decreases with the output $Q$, so we have shown that $p$ decreases in $x_{1}$.

Lemma 2 The minimal talent $t^{*}$ is increasing in the share of entrepreneurs $x_{1}$.

Proof. With simple algebra, differentiating equation (7), one can write

$$
\frac{\partial t^{*}}{\partial x_{1}}=\frac{w l}{p\left(1-x_{1}\right)^{2}}-\frac{1}{p^{2}\left(1-x_{1}\right)} \frac{\partial P}{\partial x_{1}}\left[w l+\left(1-x_{1}\right) k\right] .
$$

The first term is positive and due to Lemma 1 the second term is also positive. Hence, $t^{*}$ increases in $x_{1}$.

Lemma 3 The share of entrepreneurs $x_{1}$ is increasing in financial development.

Proof. Implicitly differentiating equation (8), we have

$$
\frac{\partial x_{1}}{\partial a^{*}}=\frac{-\frac{\partial F}{\partial a^{*}}\left[1-G\left(t^{*}\right)\right]}{1+\left[1-F\left(a^{*}\right)\right] \frac{\partial G}{\partial t^{*}} \frac{\partial t^{*}}{\partial x_{1}}} .
$$

The numerator measures the change in individuals who can afford to become entrepreneurs. The denominator tells how the mass of individuals who are sufficiently talented and so willing to be entrepreneurs changes as $x_{1}$ increases. Given Lemma $2, \partial t^{*} / \partial x_{1}$ is positive and hence $\partial x_{1} / \partial a^{*}$ is negative. Hence, the higher is financial development (i.e. the lower $a^{*}$ ), the higher is the share of entrepreneurs $x_{1}$. 
Lemma 4 From condition (12), the equilibrium collateral $a^{*}$ is implicitly defined as a fixed point of the function

$$
h\left(a^{*}\right)=b-\frac{x_{2}\left(a^{*}\right)}{1-x_{1}\left(a^{*}\right)} w .
$$

Proof. There are a priori two ways in which the collateral requirement $a^{*}$ can be set. The first is to make sure that even the least talented individual would have no incentive to divert capital, i.e. to set the minimal $a$ such that

$$
\tilde{t} \leq \underline{t} .
$$

Rearranging in terms of a lower bound on wealth, this writes as

$$
a \geq b+w l+r k-\underline{t} p .
$$

A second condition is that, conditional on asking for a loan, an individual has no incentive to divert capital, i.e. to set the minimal $a$ such that $\tilde{t} \leq t^{*}$, which is condition (12) in the text. To see which of the two conditions determines the level of collateral $a^{*}$, notice that (17) implies (12). In fact, by (9) we have that $1-G\left(t^{*}\right) \leq 1$ for every $t^{*}$. By definition, $1-G(\underline{t})=1$, so it must be that $\underline{t}<t^{*}$. Moreover, notice that our assumption of competition in the credit market ensures that in equilibrium $a^{*}$ is chosen as the minimum collateral required to make sure that capital is not diverted. Hence, the lowest level of collateral needed to get a loan is determined by condition (12).

Lemma 5 The function $h\left(a^{*}\right)$ is increasing and concave.

Proof. The proof is simple algebra. In fact, notice that

$$
\frac{\partial h\left(a^{*}\right)}{\partial x_{1}}=-\frac{l w}{\left(1-x_{1}\right)^{2}}<0,
$$

and

$$
\frac{\partial x_{1}}{\partial a^{*}}=-\frac{\partial F\left(a^{*}\right)}{\partial a^{*}} \leq 0,
$$

thus

$$
\frac{\partial h\left(a^{*}\right)}{\partial a^{*}}=\frac{\partial h\left(a^{*}\right)}{\partial x_{1}} \frac{\partial x_{1}}{\partial a^{*}} \geq 0 .
$$

Moreover,

$$
\frac{\partial^{2} h\left(a^{*}\right)}{\partial x_{1} \partial a^{*}}=-\frac{2 l w}{\left(1-x_{1}\right)^{3}} \frac{\partial x_{1}}{\partial a^{*}}>0,
$$

and, since wealth is distributed uniformly,

$$
\frac{\partial^{2} x_{1}}{\left(\partial a^{*}\right)^{2}}=0 .
$$


This implies that

$$
\frac{\partial^{2} h\left(a^{*}\right)}{\left(\partial a^{*}\right)^{2}}=\frac{\partial^{2} h\left(a^{*}\right)}{\partial x_{1} \partial a^{*}} \frac{\partial x_{1}}{\partial a^{*}}+\frac{\partial h\left(a^{*}\right)}{\partial x_{1}} \frac{\partial^{2} x_{1}}{\left(\partial a^{*}\right)^{2}}<0 .
$$

Hence, $h\left(a^{*}\right)$ is increasing and concave.

Proposition 3 If $b \in(w, k)$, then equation (13) uniquely defines an equilibrium level of financial development $a^{*} \in(0, k)$. Otherwise multiple equilibria may arise, and countries with slightly different initial conditions may experience greatly diverging development paths.

Proof. In order to characterize the levels of financial development arising in equilibrium, denote any equilibrium candidate as $\hat{a}$. Consider $\hat{a}=0$, so that $F(\hat{a})=0$. Denote the corresponding minimal entrepreneurial talent, as expressed in equation (7), as $t^{\max }$ and the corresponding share of entrepreneurs as

$$
\bar{x}_{1} \equiv 1-G\left(t^{\max }\right) .
$$

Similarly consider $\hat{a}=k$, and denote the corresponding minimal entrepreneurial talent as $t^{\min }$ and the corresponding share of entrepreneurs as

$$
\underline{x_{1}} \equiv[1-F(k)]\left[1-G\left(t^{\mathrm{min}}\right)\right]
$$

Hence

$$
h\left(a^{*}\right) \in[h(0), h(k)],
$$

where

$$
h(0) \equiv b-\frac{l \bar{x}_{1}}{1-\bar{x}_{1}} w \text { and } h(k) \equiv b-\frac{l \underline{x_{1}}}{1-\underline{x_{1}}} w .
$$

If $b \leq k$, then $h(k)<k$, which implies that $\hat{a}=k$ cannot be an equilibrium. If, $b>w$ then $h(0)>0$, which implies that $\hat{a}=0$ cannot be an equilibrium. In this case, condition (12) defines a unique equilibrium and this equilibrium is stable and interior. If instead $h(k)>k$ and $h(0)>0$, then there is no interior fixed point and the country converges to $a^{*}=k$ irrespective of initial conditions. Suppose instead that $h(k)>k$ and $h(0)<0$, then there is one interior fixed point, call it $a_{1}^{*}$, which is however unstable. Starting from any level of financial development such that $\hat{a}>a_{1}^{*}$, the economy converges to an equilibrium with no financial development $a^{*}=k$ while starting at any $\hat{a}<a_{1}^{*}$ the economy converges to the virtuous equilibrium with high financial development $a^{*}=0$. Finally, suppose that $h(k)<k$ and $h(0) \leq 0$. In this case, $a^{*}=0$ is an equilibrium and $a^{*}=k$ is not an equilibrium. Given Lemma $5, h\left(a^{*}\right)$ can have either one, two or no fixed point for $a^{*} \in(0, k)$. Suppose first that the interior fixed point is unique and call it $a_{2}^{*}$. In this case, the economy converges to $a^{*}=a_{2}^{*}$ for any $\hat{a} \geq a_{2}^{*}$ and converges to $a^{*}=0$ for any $\hat{a}<a_{2}^{*}$. A similar scenario occurs when 
there are two interior fixed points of $h\left(a^{*}\right)$. Denote them $a_{3}^{*}$ and $a_{4}^{*}$, with $a_{3}^{*}>a_{4}^{*}$. In this case, starting from any level of financial development such that $\hat{a}>a_{4}^{*}$, the economy converges to an equilibrium with low financial development $a^{*}=a_{3}^{*}$ while starting at any $\hat{a}<a_{4}^{*}$ the economy converges to the virtuous equilibrium. Finally, if there is no interior fixed point of $h\left(a^{*}\right)$, the economy converges to $a^{*}=0$ irrespective of the initial level of financial development. Notice the last scenario is more likely to occur the lower is $h(k)$ and so in particular the higher is $x_{1}$. From equation (18), this is more likely to occur when $F(k)$ is low. 